BENTHAM OPEN
CrossMark
Content list available at: www.benthamopen.com/TODENTJ/
DOI: $10.2174 / 1874210601610010315$

\title{
Prevalence of Traumatic Dental Injuries in Patients Attending University of Alberta Emergency Clinic
}

\author{
Thamer Alkhadra ${ }^{\mathrm{a}}$, William Preshing ${ }^{\mathrm{b}}$ and Tarek El-Bialy ${ }^{\mathrm{b}, *}$ \\ ${ }^{a}$ Faculty of Dentistry, King Saud University, Riyadh, Saudi Arabia \\ ${ }^{b}$ Faculty of Medicine and Dentistry, University of Alberta, Edmonton, Canada
}

Received: October 01, 2015

Revised: April 01, 2016

Accepted: May 06, 2016

\section{Abstract: \\ Objectives:}

This study evaluated the prevalence of dental trauma for patients attending the emergency dental clinic at the University of Alberta Hospital between 2006-2009. Patients' examination and treatment charts were reviewed.

\section{Methods:}

Total number of patients' charts was 1893. The prevalence of different types of trauma was $6.4 \%$ of the total cases (117 patients). Trauma cases were identified according to Ellis classification and as modified by Holland et al., 1988.

\section{Results:}

Logistic statistical model showed that $21.7 \%$ were Ellis class I trauma, $16.7 \%$ were Ellis class II trauma, and $6.7 \%$ were Ellis class III. In addition, $11.7 \%$ presented with avulsion, $7.5 \%$ presented with dentoalveolar fracture and $7.5 \%$ presented with sublaxation. Also, $17.55 \%$ presented with tooth displacement within the alveolar bone, $3.3 \%$ presented with crown fracture with no pulp involvement, $4.16 \%$ presented with crown fracture with pulp involvement and $3.3 \%$ presented with root fracture. In conclusion, the general prevalence of dentoalveolar trauma in patients attending the emergency clinic at the University of Alberta is less than other reported percentages in Canada or other countries.

Keywords: Alberta, Canada, Dentoalveolar trauma, Prevalence.

\section{INTRODUCTION}

To establish prospective treatment modalities and public awareness of potential causes and consequences of dentoalveolar trauma, it is very important to establish provincial, national and international prevalence of dental trauma and its causes. Previous reports on the prevalence of dental trauma showed different percentages of dental trauma in different parts of the world.

Early reports on the prevalence of dental trauma in 519 children between ages of 6 to -11 years old in Italy was $21 \%$ with male/female ratio of 1.69 [1]. Petti et al.1996 reported that higher dentoalveolar trauma prevalence was among the 9 year-old children (26.9\%) compared to other age groups with enamel fractures being the most frequent trauma type $(67.0 \%)$, followed by enamel-dentine fractures $(19.3 \%)$ and concussions $(8.3 \%)$. Play was the cause of major dental trauma (64.2\%), followed by sports (17.4\%). Josefsson and Karlander (1994), used Garcia-Godoy classification [2] which was described by the authors to be the most appropriate for retrospective studies. Another report on the prevalence of dental trauma in Sweden in children between 7-17 years old showed that the prevalence was $11.7 \%$ with a

\footnotetext{
* Address correspondence to this author at the Faculty of Medicine and Dentistry, University of Alberta, Edmonton, Canada; Tel: 1-(780)-492-2751; Fax: 1-(780) 492-2624; E-mail: telbialy@ualberta.ca
} 
distribution of $63 \%$ boys (highest in the $8-12$ years-old age group) and $37 \%$ girls (highest in the 7-9 year-old age group) [3] The most frequent etiological factors were collision during play, and falling over. Also, Josefsson and Karlander 1994, reported that $10 \%$ of all dental injuries were caused by violence. Noori and Al-Obadi, 2009 [4] studied traumatic dental injuries among primary school children in Iraq. They investigated 4105 students and they used dental trauma criteria as published by of Garcia-Godoy [2]. They reported that traumatic dental injuries were found to be $6.1 \%$ in Iraqi primary school children with males being $61 \%$ more than females. They suggested that this increase of dental traumatic injury in males than in females may be due to the fact that males tend to participate in more strenuous activities with higher trauma risk, such as contact and more aggressive types of sports. While an earlier study in the same country reported the prevalence of dental trauma to be $29.6 \%$ [5], it could be argued that the recent decline in the percentage of dental trauma in Iraq could be due to the increased public awareness of the significance and consequences of dental trauma. Another recent study on the prevalence of traumatic dental injuries among 12-year-old school children according to Garcia-Godoy classification of dental trauma was $12.8 \%$ in Nigeria [6]. Author et al. reported that there was no statistical difference in the prevalence between boys and girls and the most common cause of injuries was falls $(49.1 \%)$, traffic accidents $(13.2 \%)$, collision $(11.3 \%)$ and misuse of teeth $9.4 \%$. In addition, they reported that the most common type of injury was enamel fracture alone (9.9\%), followed by enamel-dentine fracture (4.8\%). Majority of the accidents occurred at home (60.4\%), followed by school (26.4\%) [6]. On the other hand, another study in South Africa in the same year evaluated dental traumatic injuries in 11-13 year-old school children using modified version of Ellis's classification. The authors reported that the percentage of traumatic injuries was $6.4 \%$ of the 1065 studied cases with boys showed 2.5 times higher than females [7]. It is to be noted that the highest prevalence was in 12 year olds and in the high socio-economic status group with enamel fracture was the main type of dental trauma (69.1\%). It is interesting to see differences within the same continent in terms of percentage of dental trauma, however there is a consistent increased figure of dental trauma in boys compared to girls.

On contrast, another study was conducted by Cavalcanti et al., 2009 that evaluated the prevalence of dental injuries in 448 7-12-year-old children in Brazil [8] using Andreasen and Andreasen [9], O'Brien [10] and Cortes [11] classifications showed that $21 \%$. Boys experienced more injuries $21.9 \%$ than girls $20 \%$ [8]. They reported that falls (63.8\%) and collisions (24.5\%) were the main causes of dental trauma. On the other hand, another report in the same year 2009, from Brazil too, however when studied dental trauma in preschool children using Ellis' classification showed that there was a 47.9\% increase in traumatic dental injuries between 2002 and 2006 in 5-59 months old children [12]. They reported that there was no significant gender, family structure, and socio-economic differences in the prevalence of dental injuries [12]. The predisposing factors that are related to dental injuries include overjet, lip coverage, and anterior overbite [12]. It has been reported that in Australia, males represented 67\% of 304 cases reported with orofacial trauma and three-quarters of all cases were aged less than 24 years [13]. These traumatic injuries are more related to sports activities. Another study about dental traumatic injuries in Thai children aged 11-13 years old revealed that $35 \%$ of the studies children had traumatic dental injuries with males as twice as females. Also, they reported that the prevalence of dental trauma increased with age with more common affected children who are living in more disadvantaged households and whose parents were less educated. Increased overjet was highly related to the increased prevalence of dental trauma among the affected children [14].

The reports about the prevalence of dental trauma in Canadian communities was limited to Ontario province [15 17]. These studies reported that the prevalence of dental trauma was $15.5 \%$. No other reports about the prevalence of dental trauma in other Canadian providences or communities could be found in the literature. Also, one study [17] was limited to the prevalence of hockey related dentofacial trauma.

With the difference in culture and different life styles between countries, it is important to report on the prevalence of dental trauma in different countries and the possible contributing factors in each country. Until now, there is no report on the provenance of dental trauma in Alberta, Canada. In order to enhance health services in Alberta, it is important to evaluate the magnitude and nature of dental trauma. This study evaluated the prevalence of dental trauma of cases attended the dentistry clinic and the University of Alberta emergency hospital between 2006 and 2009 . We hypothesized that the prevalence and severity of dental trauma in Edmonton is higher in males than in females. We also hypothesize that the prevalence and severity of dental trauma decrease with age. This is based on the previous reports in different countries that showed that prevalence of dental trauma is higher in younger age groups and also male in most studies are affected by dental trauma than females. 


\section{MATERIALS AND METHODS}

Health Ethics review board approval from the University of Alberta has been obtained for this research. To assess the prevalence of dental trauma for patients attending the emergency dental clinic at the University of Alberta Hospital between years 2006-2009, 1893 patients' charts were reviewed. All patients' charts were evaluated and cases reported with any trauma to the face and /or to the mouth were identified. Patients' examination and treatment charts were reviewed. Two independent researchers carefully reviewed the patients' charts in order to minimize possible bias in evaluating the charts. In order to overcome bias in data collection or interpretation error, twenty charts of the patients were randomly selected and traumatic injury classifications for these charts were compared between the two researchers' scores using Pearson's correlation coefficient. The trauma cases were identified according to Ellis classification [18] as modified by Holland et al., 1988 [19] as follows: Class 1: Fracture of enamel only; Class 2: Fracture of enamel and dentine, without pulp involvement; Class 3: Fracture of enamel and dentine with pulp involvement; Class 4: Discoloration of the tooth as a result of concussion to the tooth, with or without a sinus tract; Class 5: Displacement, extrusion, intrusion and lateral displacement; class 6: Tooth loss as a result of trauma and class 7: Tooth restored by composite or crown restoration following fracture.

To evaluate the association of 'Age' and the trauma types, the correlation coefficient was calculated. The trauma type is ordinal data and the 'Age' is interval data. Three methods of correlation are provided using Spearman's rho statistic (non-parametric statistical test) using SPSS statistical package, Version 17, SPSS, IL, USA). Spearman's rho statistical analysis is recommended for studies similar to this study since the data do not come from a bivariate normal distribution. The statistical approach used for evaluating the effects of 'Age' and 'Sex' on the trauma levels is ordinal logistic regression.

\section{RESULTS}

Based on the correlations, there was no obvious association between 'Age' and trauma levels.

The prevalence of different types of trauma was $6.4 \%$ of the total cases (120 patients). $21.7 \%$ of the cases presented with Ellis Class I trauma, 16.7\% of the cases presented with Ellis Class II trauma, and 6.7\% presented with Ellis Class III trauma. $11.7 \%$ presented with tooth avulsion, $7.5 \%$ presented with dentoalveolar fracture and $7.5 \%$ presented with sublaxation. $17.55 \%$ presented with tooth displacement within the alveolar bone, 3.3 presented with crown fracture with no pulp involvement, $4.16 \%$ presented with crown fracture with pulp involvement and 3.3\% presented with root fracture. The most prevalence trauma was Ellis Class I, followed by tooth displacement then tooth avulsion. The least prevalent reported trauma was crown fracture with no pulp involvement. The highest proportion of traumatized children was found with proclined upper incisors and involvement of hockey related trauma. Falls and playing were the most common causes of dental trauma. Viewing these results with regard to patient's ages, the female population reported with trauma has age range between 1-85 years with average 26 years and 10.8 month \pm 19 years and 10 months. Using independent t-test with Levene's Test for Equality of Variances, there was a statistically significant difference between the males and females with regards to their ages. The age of the traumatized males however ranges from 1-69 years with average age 24 years and 7.2 months \pm 14 years and 2.4 months. The prevalence of dental traumatic injury however was more frequent in males (83 subjects [70.9\%]) than in females (34 subjects [29.1\%]).

Table 1. Correlations between gender and type of trauma in pooled data (males and females).

\begin{tabular}{|c|c|c|}
\hline Measure of correlation & Correlation coefficient & Test of significant \\
\hline Spearman's rho & -0.1 & $\mathrm{~S}=3$ \\
\hline
\end{tabular}

Table 2. Correlations between types of trauma in female group.

\begin{tabular}{|c|c|c|}
\hline Measure of correlation & Correlation coefficient & $\boldsymbol{P}$-value \\
\hline Spearman's rho & -0.2 & 0.3 \\
\hline
\end{tabular}

Table 3. Correlations between severities of trauma in male group.

\begin{tabular}{|c|c|c|}
\hline Measure of correlation & Correlation coefficient \\
\hline Spearman's rho & -0.1 & \\
\hline
\end{tabular}


Fig. (1) shows the distribution of the cases for the 7 different levels of trauma in this study. The distributions of cases separated by 'Sex' are shown in the Fig. (2). From this figure, it can be seen that the effect of 'Sex' on the classification of trauma is significant. Fig. (3) presents a box plot showing comparison of dental trauma distribution between males and females in different age groups. Fig. (4) shows the correlation between age and trauma type for males and females. Spearman's rho statistic is recommended for this study since the data does not come from a bivariate normal distribution. Based on the correlations, there is no obvious association between 'Age' and trauma levels (Tables 1 - 3).

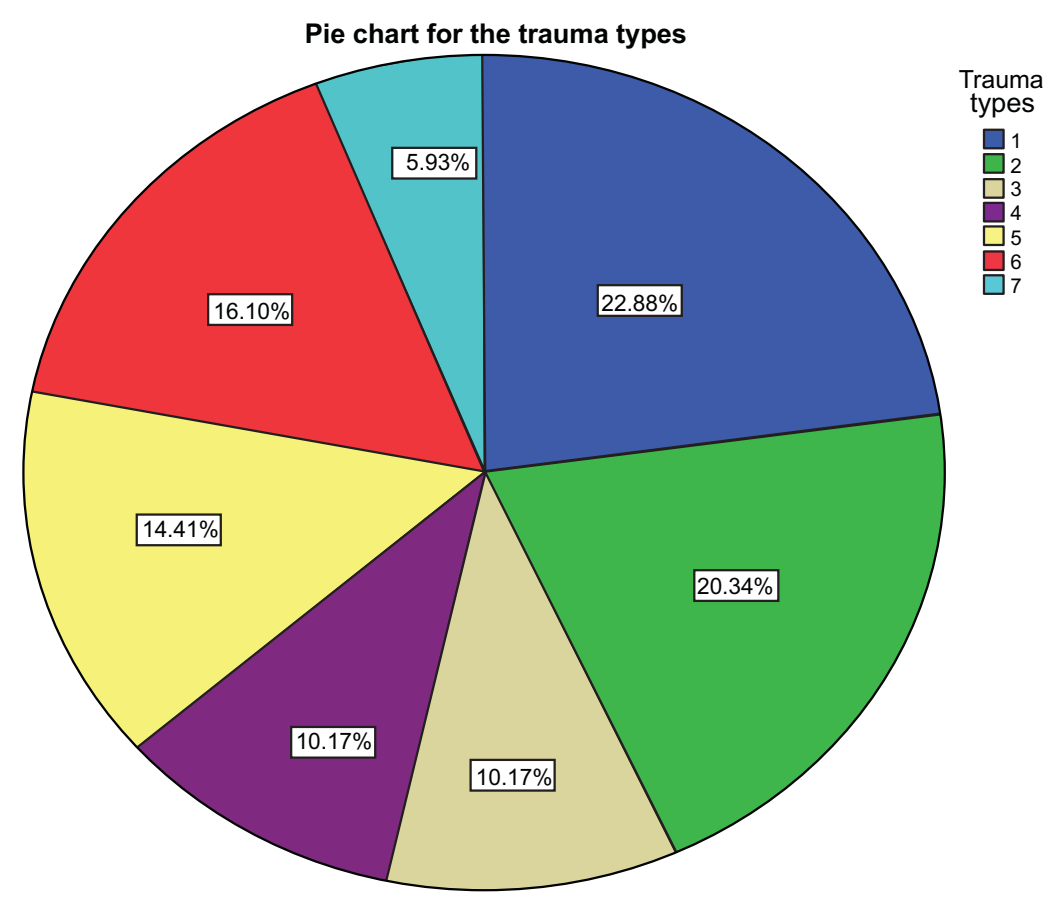

Fig. (1). Distribution of dental trauma according to Ellis classification. It can be noticed that types 1 and 2 are the most common types of trauma in Edmonton.

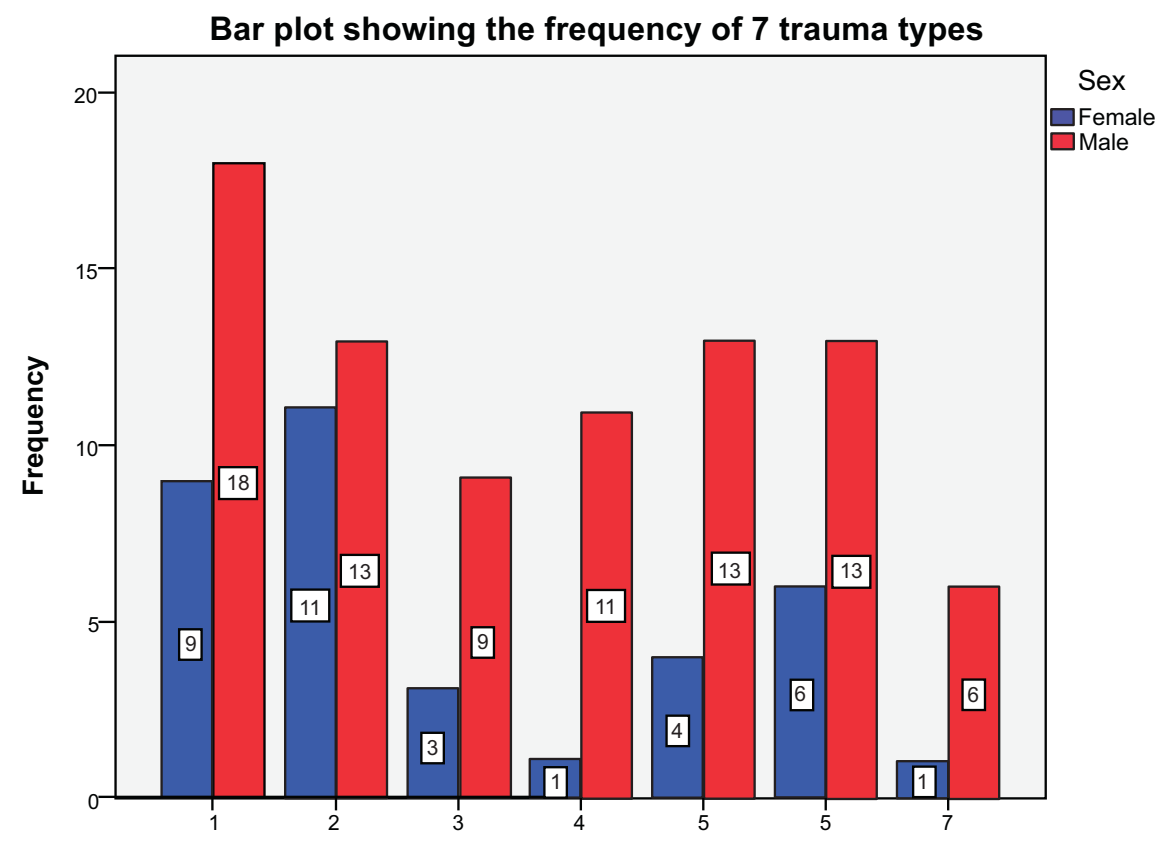

Fig. (2). Distribution of dental trauma according to Ellis classification between males and females. It can be seen that males have consistently increased prevalence of trauma than females in all types of trauma. 


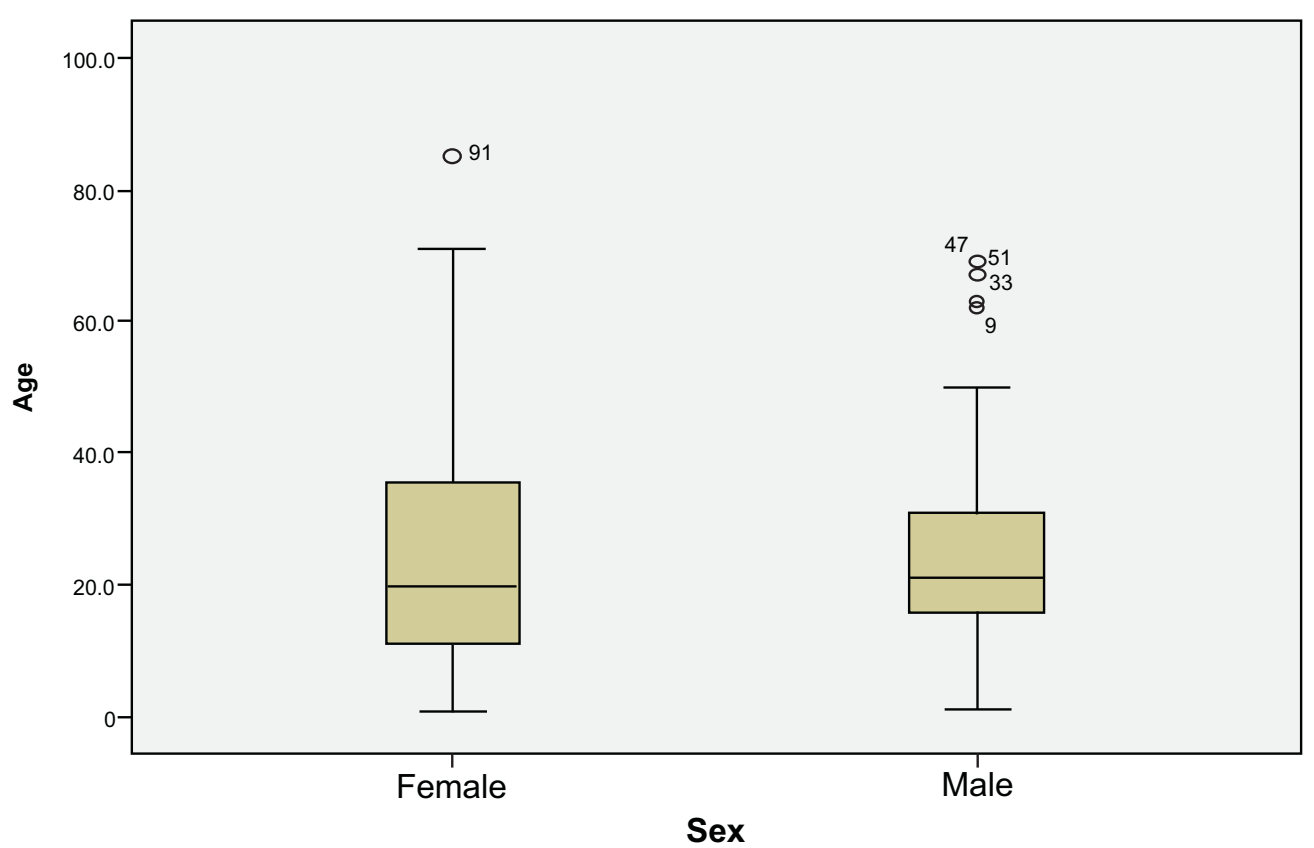

Fig. (3). Box plot showing comparison of dental trauma distribution between males and females in different age groups. It can be seen that males have higher total prevalence of trauma than females.

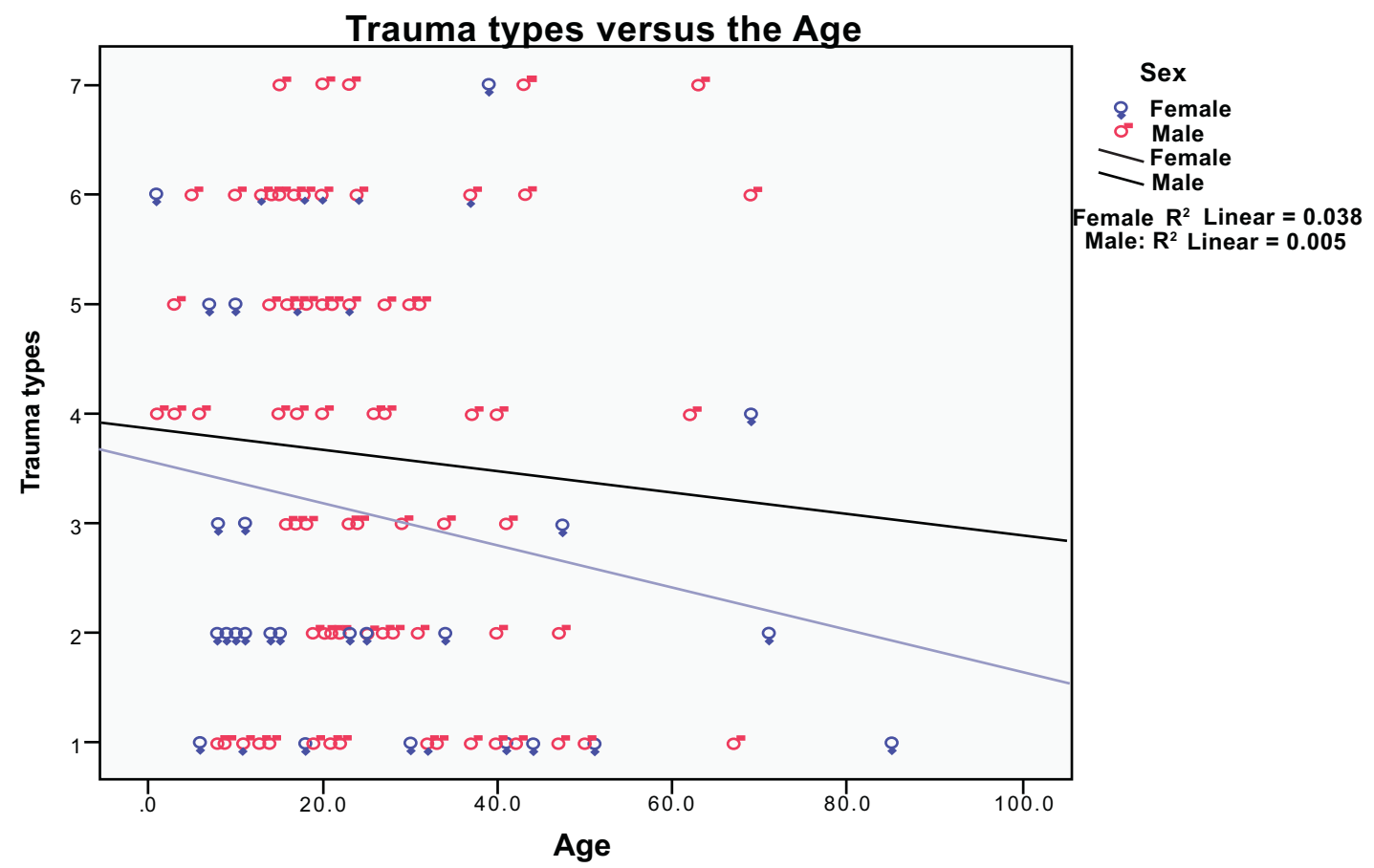

Fig. (4). Correlation between age and trauma type for males and females. It can be seen that males presented with trauma were older than females who presented with trauma.

Using ordinal logistic regression, the coefficients for 'Age' and 'Sex' were $-0.01528(p=0.1546)$ and 0.45031 $(p=0.2092)$, respectively. With a significance level of 0.05 , the two effects are both insignificant on the levels of the trauma.

\section{DISCUSSION}

Although there are many dental trauma classifications available in the literature, it has been recommended recently, 
based on a systematic review of dental trauma classification systems, that Ellis classification is the most appropriate classification system for epidemiological studies [20]. It has been reported that some of these systems are nonapplicable in epidemiological studies, due to some particular characteristics, i.e. radiographic examination as a part of the clinical examination; diagnosis of root fractures, pulp vitality and sinus tracts. Moreover, some of them include many broad terms, detailed terms, or very controversial ones. In addition, it has been concluded that Ellis' classification system, is the most suitable for epidemiological studies. The Aim of the current manuscript was to report the prevalence and types of dental traumatic injuries in Edmonton, Alberta according to Ellis Classification of dental trauma and its modification by Holland et al., 1988 [19].

The prevalence of dentoalveolar trauma at the emergency dental clinic at the University of Alberta hospital in this study revealed $6.4 \%$ of the total patients attended the emergency clinic. This percentage is comparable to that of a South Africa report (add reference). In comparison to different reports of the prevalence of dental trauma, Alberta may be considered the lowest prevalence in the world. Based on the statistical analysis of the presented data, the null hypothesis that there is no relationship between severity of dental trauma and gender is rejected. Also, the null hypothesis that there is no relationship between severity of dental trauma and age is rejected. The relatively increased prevalence of Ellis class I, 2 and 5, 6 could be explained by the understanding that trauma occur due to increased involvement of younger generation in sports that do not enforce safety precautions (wearing mouth guards in case of soccer for example), with particular increase prevalence in males than in females. This may also be attributed to the decreased involvement of younger females in aggressive sports than males.

\section{SUMMARY}

The present study presents a relatively low prevalence of dental trauma, but still this low percentage represents a large number of patients. This study suggests initiation and implementation of public awareness studies that aims towards prevention and potential treatment strategies of dentoalveolar traumatic injuries.

\section{CONFLICT OF INTEREST}

The authors confirm that this article content has no conflict of interest.

\section{ACKNOWLEDGEMENTS}

The authors would like to acknowledge Mary-Ellen Polymeris and Shanie Maharaj for their help with collecting data. Also, the authors would like to thank Dr. Giseon Heo and Yin Li for their help with statistical analysis.

\section{REFERENCES}

[1] Petti S, Tarsitani G, Arcadi P, Tomassini E, Romagnoli L. The prevalence of anterior tooth trauma in children 6 to 11 years old. Minerva Stomatol 1996; 45(5): 213-8.

[PMID: 8926989]

[2] García-Godoy F. A classification for traumatic injuries to primary and permanent teeth. J Pedod 1981; 5(4): $295-7$. [PMID: 6121021]

[3] Josefsson E, Karlander EL. Traumatic injuries to permanent teeth among Swedish school children living in a rural area. Swed Dent J 1994; 18(3): 87-94. [PMID: 7916166]

[4] Noori AJ, Al-Obaidi WA. Traumatic dental injuries among primary school children in Sulaimani city, Iraq. Dent Traumatol 2009; 25(4): 442-6. [http://dx.doi.org/10.1111/j.1600-9657.2009.00791.x] [PMID: 19496800]

[5] Al-Hayali A. Traumatized anterior teeth among 4-11 years old in the central region of Iraq. MSc thesis. Baghdad: College of Dentistry, University of Baghdad 1998.

[6] Adekoya-Sofowora CA, Adesina OA, Nasir WO, Oginni AO, Ugboko VI. Prevalence and causes of fractured permanent incisors in 12-yearold suburban Nigerian schoolchildren. Dent Traumatol 2009; 25(3): 314-7. [http://dx.doi.org/10.1111/j.1600-9657.2008.00704.x] [PMID: 19302204]

[7] Naidoo S, Sheiham A, Tsakos G. Traumatic dental injuries of permanent incisors in 11- to 13-year-old South African schoolchildren. Dent Traumatol 2009; 25(2): 224-8. [http://dx.doi.org/10.1111/j.1600-9657.2008.00749.x] [PMID: 19290905]

[8] Cavalcanti AL, Bezerra PK, de Alencar CR, Moura C. Traumatic anterior dental injuries in 7- to 12-year-old Brazilian children. Dent Traumatol 2009; 25(2): 198-202. [http://dx.doi.org/10.1111/j.1600-9657.2008.00746.x] [PMID: 19290900] 
[9] Andreassen JO, Andreasen EM. Textbook and color atlas of traumatic injuries to the teeth. $3^{\text {rd }}$ ed. St. Louis, MO: Mosby 1994 ; p. 771.

[10] O’Brien M. Report of Dental Survey. Office of Population Censuses and Surveys. London: Her Majesty’s Stationery Office; 1994. Children's Dental Health in the United Kingdom 1993.

[11] Cortes MI, Marcenes A, Sheiham W. Impact of traumatic injuries to the permanent teeth on the oral health-related quality of life in 12-14year-old children. Community Dent Oral Epidemiol 2002; 30(3): 193-8. [PMID: 12000342]

[12] de Vasconcelos CBGA, Marcenes W, Oliveira LB, Sheiham A, Bönecker M. Trends in the prevalence of traumatic dental injuries in Brazilian preschool children. Dent Traumatol 2009; 25(6): 594-8. [http://dx.doi.org/10.1111/j.1600-9657.2009.00826.x] [PMID: 19788423]

[13] Tham RC, Cassell E, Calache H. Traumatic orodental injuries and the development of an orodental injury surveillance system: a pilot study in Victoria, Australia. Dent Traumatol 2009; 25(1): 103-9. [http://dx.doi.org/10.1111/j.1600-9657.2008.00720.x] [PMID: 19208021]

[14] Malikaew P, Watt RG, Sheiham A. Prevalence and factors associated with traumatic dental injuries (TDI) to anterior teeth of 11-13 year old Thai children. Community Dent Health 2006; 23(4): 222-7. [PMID: 17194069]

[15] Locker D. Self-reported dental and oral injuries in a population of adults aged 18-50 years. Dent Traumatol 2007; 23(5): 291-6. [http://dx.doi.org/10.1111/j.1600-9657.2006.00457.x] [PMID: 17803486]

[16] Locker D. Prevalence of traumatic dental injury in grade 8 children in six Ontario communities. Can J Public Health 2005; 96(1): 73-6. [PMID: 15682702]

[17] Benson BW, Mohtadi NG, Rose MS, Meeuwisse WH. Head and neck injuries among ice hockey players wearing full face shields $v s$ half face shields. JAMA 1999; 282(24): 2328-32. [http://dx.doi.org/10.1001/jama.282.24.2328] [PMID: 10612320]

[18] Ellis RG. The classification and treatment of injuries to the teeth of children. Chicago: Year Book Medical Publishers 1945.

[19] Holland T, O’Mullane D, Clarkson J, O’Hickey S, Whelton H. Trauma to permanent teeth of children, aged 8, 12 and 15 years, in Ireland. J Paediatr Dent 1988; 4(1): 13-6. [PMID: 2908333]

[20] Feliciano KM, de França Caldas A Jr. A systematic review of the diagnostic classifications of traumatic dental injuries. Dent Traumatol 2006; 22(2): 71-6. [http://dx.doi.org/10.1111/j.1600-9657.2006.00342.x] [PMID: 16499629]

(C) Alkhadra et al. ; Licensee Bentham Open.

This is an open access article licensed under the terms of the Creative Commons Attribution-Non-Commercial 4.0 International Public License (CC BY-NC 4.0) (https://creativecommons.org/licenses/by-nc/4.0/legalcode), which permits unrestricted, non-commercial use, distribution and reproduction in any medium, provided the work is properly cited. 